Authors have nothing to disclose with regard to commercial support.

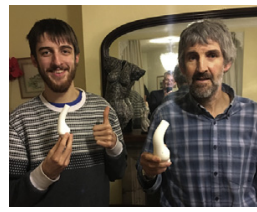

\section{PLAN, SCAN, MODEL, PRINT, MANUFACTURE, AND IMPLANT PERSONALIZED EXTERNAL AORTIC ROOT SUPPORT (PEARS)}

\section{To the Editor:}

New technologies of their nature present previously unimagined opportunities. In the case of 3-dimensional (3D) printing, the opportunity is to do more precisely planned, individualized procedures. ${ }^{1}$ In 2000 when the engineer Tal Golesworthy stood up in an audience of people with Marfan syndrome and their families, to question the lecturer (T.T.), he spoke in a language that we surgeons did not understand. "Computer-aided design" and "rapid prototyping" were arcane phrases ${ }^{2}$ but, now known as 3D printing, the concept and its implementation are easier to grasp.

The central picture makes the point. The 2 men are father and son. Each is holding a 3D printed copy of his ascending aorta. Both have the morphology that we associate with Marfan syndrome. In the 37-year difference in their ages, the father's had become dangerously large; the son's would inevitably have followed a similar trajectory. The father's and the son's aortic models were used to manufacture the mesh sleeve that was implanted around their aortas in December 2016, 12 days before this picture was taken. The rigid 3D models, on which the sleeve was made, have now done their job, and the 2 men have them to take home.

As elegantly demonstrated by Hermsen and colleagues, ${ }^{1}$ it is now possible to have a 3D replica of the anatomy so that thinking, planning, and (in their instance) rehearsing the operation, can be done in advance. This diminishes the need for "workmanship of risk" and brings the surgical operation closer to the "workmanship of certainty." 3 We no longer accept "trial and error" as the surgeon's lot in life: we have to reduce error to a minimum. The less time that that is spent thinking it out and making tentative

The Editor welcomes submissions for possible publication in the Letters to the Editor section that consist of commentary on an article published in the Journal or other relevant issues. Authors should: • Include no more than 500 words of text, three authors, and five references. $\bullet$ Type with double-spacing. $\bullet$ See http://jtcs.ctsnetjournals.org/ misc/ifora.shtml for detailed submission instructions. • Submit the letter electronically via jtcvs.editorialmanager.com. Letters commenting on an article published in the JTCVS will be considered if they are received within 6 weeks of the time the article was published. Authors of the article being commented on will be given an opportunity of offer a timely response ( 2 weeks) to the letter. Authors of letters will be notified that the letter has been received. Unpublished letters cannot be returned. surgical steps against clock, the smaller is the degree of collateral damage of lengthy operations and the nearer we get to an ideal anatomical result.

A 3D modeled Personalized External Aortic Root Support (ie, PEARS) has now been in implanted in more than 99 people followed for approaching 356 patient years. The closeness of the fit allows complete incorporation of the mesh support, ${ }^{4}$ stabilization of the aortic dimensions, ${ }^{5}$ and maintenance of aortic valve competence. The precision manufacturing made possible by $3 \mathrm{D}$ printing has made this a personalized approach with a predictable result.

\section{Tom Treasure, $M S, M D, F R C S, F R C P^{a}$ \\ Conal Austin, FRCS ${ }^{b}$ \\ John Pepper, FRCS, MChir \\ ${ }^{a}$ Clinical Operational Research Unit \\ Department of Mathematics University College London \\ ${ }^{b}$ Cardiac Surgery \\ St Thomas' Hospital \\ ${ }^{c}$ Cardiac Surgery \\ Royal Brompton Hospital \\ London, United Kingdom}

\section{References}

1. Hermsen JL, Burke TM, Seslar SP, Owens DS, Ripley BA, Mokadam NA, et al. Scan, plan, print, practice, perform: development and use of a patient-specific 3-dimensional printed model in adult cardiac surgery. J Thorac Cardiovasc Surg. 2017;153:132-40.

2. Golesworthy T, Lamperth M, Mohiaddin R, Pepper J, Thornton W, Treasure T. A jacket for the Marfan's aorta. Lancet. 2004;364:1582.

3. Pye D. The Nature and Art of Workmanship. Cambridge: Cambridge University Press; 1968.

4. Treasure T, Petrou M, Rosendahl U, Austin C, Rega F, Pirk J, et al. Personalized external aortic root support: a review of the current status. Eur J Cardiothorac Surg. 2016;50:400-4.

5. Treasure T, Pepper J, Mohiaddin R. Personalised external aortic root support: letter. N Engl J Med. 2015;372:979-80.

http://dx.doi.org/10.1016/j.jtcvs.2017.03.037

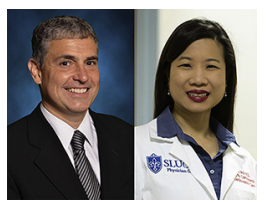

\section{PLOWING WITH UNICORNS}

Reply to the Editor:

"Innovation is not just novelty; it is novelty that works."

— Joshua Sharfstein

"It is easy to be mesmerised by the purported benefits of the digital age."

— Douglas Ruschkoff

We read with interest the letter by Treasure, Austin, and Pepper $^{2}$ and congratulate them on their early results with 